\title{
A visual energy performance assessment and decision support tool for dwellings
}

\author{
Amit Mhalas*, Mohamad Kassem, Tracey Crosbie and Nashwan Dawood
}

\begin{abstract}
Background: The target for carbon dioxide $\left(\mathrm{CO}_{2}\right)$ emissions reduction in the UK is set at $20 \%$ by 2020 and $80 \%$ by 2050. The UK housing stock is one of the least energy efficient in Europe. The energy used in homes accounts for more than a quarter of energy use and carbon dioxide emissions in Great Britain. Therefore, it is imperative to improve the energy performance of the existing housing stock and fully exploit energy efficiency and renewable energy interventions. The UK has developed several policies and initiatives to improve the energy performance of the housing stock and there are a number of databases that hold information about the condition of the housing stock. However, existing approaches and tools do not allow decision makers to assess the environmental and economic effectiveness of $\mathrm{CO}_{2}$ reduction strategies at the neighbourhood level.

Methods: This research presents a methodology that integrates these energy databases with visualisation systems and multi-criteria decision analyses to enable the evaluation of the environmental and financial implications of various energy efficiency and renewable energy interventions at both building and neighbourhood levels. The methodology is prototyped in a proof-of-concept tool which is validated and tested in an empirical case study with local authorities and social housing providers.

Results: The validation study compared the energy performance of the dwellings estimated by the proposed methodology with the energy performance calculated from actual survey and confirmed that the results are consistent. The case study demonstrated that the methodology and the prototype can be reliably utilised to evaluate the environmental and financial implications of various energy efficiency and renewable energy interventions.
\end{abstract}

Conclusion: The findings illustrate that the tool is particularly useful for town planners, local authorities and social housing providers. They can make informed decisions about the implementation of energy policies and initiatives along with energy suppliers, building engineers and architects. The tool developed in the research and presented in this paper can contribute to meeting $\mathrm{CO}_{2}$ emission reduction targets.

Keywords: Geographic Information System (GIS); Domestic energy assessment; Standard Assessment Procedure (SAP)

\section{Introduction}

There is a rising interest in tackling climate change. Subsequent to the 1992 Kyoto Protocol there is a growing incentive to reduce $\mathrm{CO}_{2}$ emissions through increased use of renewable energy sources and reducing energy demand. The UK's commitment under the protocol is for a reduction in greenhouse gas emissions of $12.5 \%$ from 1990 levels by 2012. The UK government in its Climate

\footnotetext{
* Correspondence: a.mhalas@tees.ac.uk

Technology Futures Institute, Teesside University, Middlesbrough TS1 3BA, UK
}

Change Act is committed to reduce its $\mathrm{CO}_{2}$ emissions by $80 \%$ by 2050 over its 1990 baseline (H.M. Government 2008). The UK government is also committed to meet the EU target to reduce its $\mathrm{CO}_{2}$ emissions by $20 \%$ and obtain $15 \%$ of energy from renewable sources by 2020 (House of Lords 2008).

Buildings contribute almost a half of all $\mathrm{CO}_{2}$ emissions in the UK. Of those emissions 17\% come from approximately 26 million residential dwellings and 18\% come from 2 million non-domestic buildings (All Party Urban Development Group 2008). It is expected that about 
$75 \%$ of the existing domestic stock will be still present in 2050 (Wright 2008). The UK housing stock is one of the oldest and the least efficient in Europe. This poor quality housing stock means space heating consumed about $66 \%$ of the total delivered energy in 2006 (Palmer and Cooper 2011). Over 30\% of the dwellings in England are thought to be 'non-decent' i.e. they are unhealthy, in disrepair, in need of modernisation or providing insufficient thermal comfort, with $80 \%$ of these failing to meet the criteria for comfort (Communities and Local Government 2012). The reduction of $\mathrm{CO}_{2}$ emissions from the existing built environment is likely to be a key component of meeting the overall $80 \% \mathrm{CO}_{2}$ emissions reduction target (Jones et al. 2007).

A range of improvements through energy efficiency and renewable energy measures is promoted through Government policies and initiatives including Carbon Emissions Reduction Targets (CERT), Community Energy Savings Programme (CESP), Energy Company Obligation (ECO) and the Green Deal (DECC 2009). These initiatives include grants and advice programmes to achieve short and long term emission goals. These initiatives aim to reduce energy consumption, improve living standards and eliminate fuel poverty (DECC 2011a, b). The local development framework requires local governments to involve local community, utility providers, environmental groups and housing corporations amongst others in their appraisal and management process of the framework (Office of the Deputy Prime Minister 2010). Therefore, energy and carbon models which can undertake predictions and evaluate the potential of different energy efficiency and renewable energy interventions for the housing stock are essential for implementation of these policies and initiatives (Cheng and Steemers 2011).

This paper presents a methodology and a proof-of-concept tool that together integrates energy databases with visualisation systems and multi-criteria decision analyses to enable the evaluation of the environmental and financial implications of various energy efficiency and renewable energy interventions at both building and neighbourhood levels. The proof-of-concept tool is based on a GIS platform and makes use of aerial and terrestrial imagery, digital maps and information from various national statistics and databases. First, the paper presents the gaps identified through literature review of the existing dwelling models. Second, the paper illustrates the methodology and tool developed and their validation in an empirical case study with the involvement of a local authority and a social housing provider. Finally, the discussion of the case study results is presented conducted by comparing the tool outputs with the actual energy performance data from the housing provider and estimating the potential of energy saving and $\mathrm{CO}_{2}$ emission reduction.

\section{Background}

The techniques to model energy consumption in the residential sector can be broadly classified into 'top-down' and 'bottom-up' approaches (Tuladhar et al. 2009). The approaches have a vast diversity in terms of their level of detail, their complexity, the data input required by the user, the time periods covered and their geographical coverage (Hourcade et al. 2006).

\section{Top down approaches}

The top-down approaches work on a macro-economic scale to model energy supply and energy demand. The development and use of these approaches grew significantly during the energy crisis in the late 1970s. The models require few details of the consumption process and treat dwellings as an energy sink and regress or apply factors that affect consumption to determine the trends (Swan and Ugursal 2009). This approach aims at fitting historical time series of national energy consumption or $\mathrm{CO}_{2}$ emissions data on an aggregated level. Top-down models investigate the inter-relationship between the energy sector and the economy at large (Kavgic et al. 2010).

The strength of the top-down approach is that only aggregated data is required, which is widely available. The weakness of this approach is that it cannot model energy consumption at the building level and has no inherent capability to model discontinuous advances in technology (Swan and Ugursal 2009). Model developed by (Hirst et al. 1977) is sensitive to major demographic and economic factors, however these factors need to be continually updated to improve quality of the results. Haas and Schipper (1998) in their study identified "nonelastic response due to irreversible improvements in technical efficiency." It has been pointed out that a reliance on the past energy energy-economy interactions to predict future scenarios may not be appropriate while dealing with issues such as climate change; as the environmental, social and economic conditions may be significantly different to those experienced in the past (Kavgic et al. 2010). Several economists using top-down modelling approaches rely overly on the Autonomous Energy Efficiency Index leading to implementation costs for measures to mitigate $\mathrm{CO}_{2}$ emissions being over estimated (Jaccard et al. 1996).

Due to these limitations, the top-down approach is clearly not suitable for identifying key areas for improvements in the demand side energy consumption at the building level (Swan and Ugursal 2009).

\section{Bottom-up approaches}

Bottom-up approaches consist of models that use input data from highly disaggregate components. Energy consumption from units such as individual houses, or groups of houses are considered and then extrapolated to regional 
or national levels. Based on the data input, these models can be further categorised into statistical models and building physics based models.

Statistical modelling relies on the availability of large quantities of energy supplier billing data. The data is however private information and may not be widely available (Swan and Ugursal 2009). Regression analysis is typically used within statistical modelling to determine the coefficients of the model corresponding to the input parameters to estimate the energy consumption of dwellings (Fung 2003). Though these models assess the energy consumption of residential sector, they have limited abilities to assess the impact of scenarios of reduction in energy consumption (Fung 2003).

The Building physics based models calculate the energy consumption based on physical characteristics of the buildings or its components. The energy calculation requires quantitative data on physically measurable variables. These include the efficiency of space heating systems and their characteristics, information on the areas of the different dwelling elements (walls, roof, floor, windows, doors) along with their thermal characteristics (U-values), internal temperatures and heating patterns, ventilation rates, energy consumption of appliances, number of occupants, external temperatures, etc. (Johnston 2003). The combination of building physics and empirical data from housing surveys, national data sets and assumptions about buildings operation, give modellers the means to estimate energy consumption in dwellings for the past, present, and future (Wilson and Swisher 1993).

The building physics based models consider detailed information about the building and hence estimate energy consumption with most clarity (Larsen and Nesbakken 2004). Furthermore, they do not depend upon historical values; however, the historical data can be used to calibrate the models. The major advantage of building physics based models are the modular structure of their algorithms. This means the users of this approach can easily modify the algorithms to suit particular needs (Kavgic et al. 2010). Building physics based models are the only methods that can fully estimate energy consumption of a sector without historical energy consumption information and evaluate the impact of new technologies (Swan and Ugursal 2009). The policies and initiatives such as CERT, CESP, ECO and Green Deal require practical decisions and are directed towards the level of the physical factors which influence energy use. Bottom-up approaches and in particular the building physics based models help in addressing these needs and hence is the preferred approach in this study.

Several building physics based models have been developed in the UK over a number of years to estimate the current and future residential demand. Some of the notable models include:

- Building Research Establishment's Housing Model for Energy Studies (BREHOMES) (Shorrock and Dunster 1997)

- The Johnston Energy and $\mathrm{CO}_{2}$ Emission Model (Johnston 2003)

- The UK Domestic Carbon Model (UKDCM) (Boardman et al. 2005)

- The DECarb Model (Natarajan and Levermore 2007)

- The Energy and Environmental Prediction (EEP) Tool (Jones et al. 2007)

- The Community Domestic Energy Model (CDEM) (Firth et al. 2010)

- The Domestic Energy Carbon Counting and Carbon Reduction Model (DECoRuM) (Gupta 2009)

All these models have the same energy calculation engine which is the BREDEM (Building Research Establishment Domestic Energy Model) modified to varying degrees. The disaggregation levels vary significantly amongst the seven models. The transparency of models in terms of data sources and model structures is recognised by most authors as a crucial issue for the future deployment of the models. Furthermore, no access is available to the raw input data and core calculation algorithms of almost all the models, including the modified BREDEM-type modules (Kavgic et al. 2010; Natarajan and Levermore 2007). Except for EEP all other models, these tools lack the ability to be used by stakeholders for implementation of policy or initiatives.

Discussions were undertaken with stakeholders such as social housing providers, local councils, town planners and energy companies to understand how these models are currently used. Those questioned indicated that none of the models described above are used by them as the models cannot simulate scenarios for performance improvement for specific geographic areas. Further, the models rely on standard archetypes for simulation or use drive-by surveys to determine archetypes. In the case of the EEP tool it was necessary to collect data for 55,000 dwellings via a drive-by survey which took 18 months (Jones et al. 2007). Drive-by surveys are time consuming and costly. Furthermore, none of the models take into consideration the engagement of local community, utility providers, environmental groups and housing corporations as part of their decision making process (Kassem et al. 2012).

This research addresses these gaps through developing a methodology and proof-of-concept tool that integrates energy databases with visualisation systems and multicriteria analyses. For this purpose, the Standard Assessment Procedure (SAP) was selected as a main element 
of the proof-of-concept tool. SAP is underpinned by BREDEM and is the recommended tool by the Department of Energy and Climate Change (DECC) for assessing and comparing the energy and environmental performance of dwellings. SAP is now the UK's National Calculation Methodology, meeting one of the requirements of the EU Energy Performance of Buildings Directive (DECC/BRE 2010). SAP provides indicators of energy performance through energy consumption per unit floor area, an energy cost rating (the SAP rating), an Environmental Impact rating based on $\mathrm{CO}_{2}$ emissions (the EI rating) and Dwelling $\mathrm{CO}_{2}$ Emission Rate (DECC/ BRE 2010).

The methodology and the proof-of-concept tool enable stakeholders assess the baseline energy performance of dwellings on a neighbourhood level through use of visualisation techniques and databases. This eliminates the need for drive-by surveys and users can create customised archetypes representing the actual characteristics of dwellings rather than relying on standard archetypes. The tool permits stakeholders to develop tailor-made scenarios of energy efficiency and renewable energy interventions for individual or multiple dwellings thus assisting in the policy implementation stages. The tool informs the stakeholders of the environmental benefits in terms of increased SAP rating of dwellings, energy saved in $\mathrm{kWh}$ and amount of $\mathrm{CO}_{2}$ reduced in $\mathrm{kg}$ for tailor-made energy performance improvement scenarios. Most importantly, the tool incorporates the use of multi-criteria decision analysis technique which assists stakeholders in meeting the requirements of the local development framework (Office of the Deputy Prime Minister 2010) through incorporation of a tradeoff mechanism based on environmental, technical, economic and social criteria.

\section{Methods}

Within the SAP model the calculation is based on the energy balance of dwellings and considers the following factors:

- Materials used for construction of the main aspects of the dwelling such as walls, windows and roofs;

- Thermal insulation characteristics of the building fabric;

- Ventilation characteristics of the dwelling and ventilation equipment;

- Efficiency and control of the heating system(s)

- Gains into the dwellings from solar radiation, metabolism, cooking and lights and appliances;

- Fuel used to provide space and water heating, ventilation and lighting;

- Energy for space cooling, if applicable;

- Renewable energy technologies.
SAP requires an input of over 80 different items of data for each dwelling. These data are easily available for new developments; however, for existing dwellings, most of these data has to be gathered through site surveys. A detailed property survey by a trained assessor can last for at least 30 minutes (Rylatt et al. 2003). Thus collecting this data for each dwelling and then aggregating for locality, town, city, region, etc. can be hugely time consuming and expensive. To overcome this challenge, the research makes use of information from aerial and terrestrial imagery, published databases such as Homes Energy Efficiency Database (HEED), household surveys such as English House Condition Survey (EHCS), census and the Office of National Statistics (ONS). Data from these sources form input for the core SAP calculation engine. The framework used for developing the proof-of-concept tool is depicted in Figure 1.

Models of the dwellings in a neighbourhood are developed as a first step in this process. Next, energy performance calculations are undertaken for each of these dwelling models based on SAP algorithms. Based on the existing characteristics of the dwelling, the potential for carbon reduction is quantified. Finally, the energy improvement measures are ranked using a decision support system.

The prototype tool is built on a GIS platform as it helps in integrating and managing vast and various formats of data and can connect various data sets together by common locational data e.g. address (Goodchild 2009). The database created can be shared for various purposes including modelling and simulating scenarios. For the present research, ArcGIS 10 was used. It is one of the most commonly used GIS platforms and supports the data from the identified sources. ArcGIS 10 provides a geoprocessing functionality which allows personalizing tasks through inherent programming capabilities (Environmental Systems Research Institute 2010).

\section{Create domestic dwelling models}

The principal requirement of the prototype is to develop domestic dwelling models which act as source for the energy performance calculations. An investigation of the SAP algorithms reveals that the energy calculations and the data input work on three sub models. These submodels are described below and the working mechanism is depicted in Figure 2.

- Geometric sub-model consisting of details on footprint, floor height, exposed perimeter and wall area and roof-area;

- Physics sub-model consisting of details on ventilation and $U$-values of walls, windows, roof and floors; 


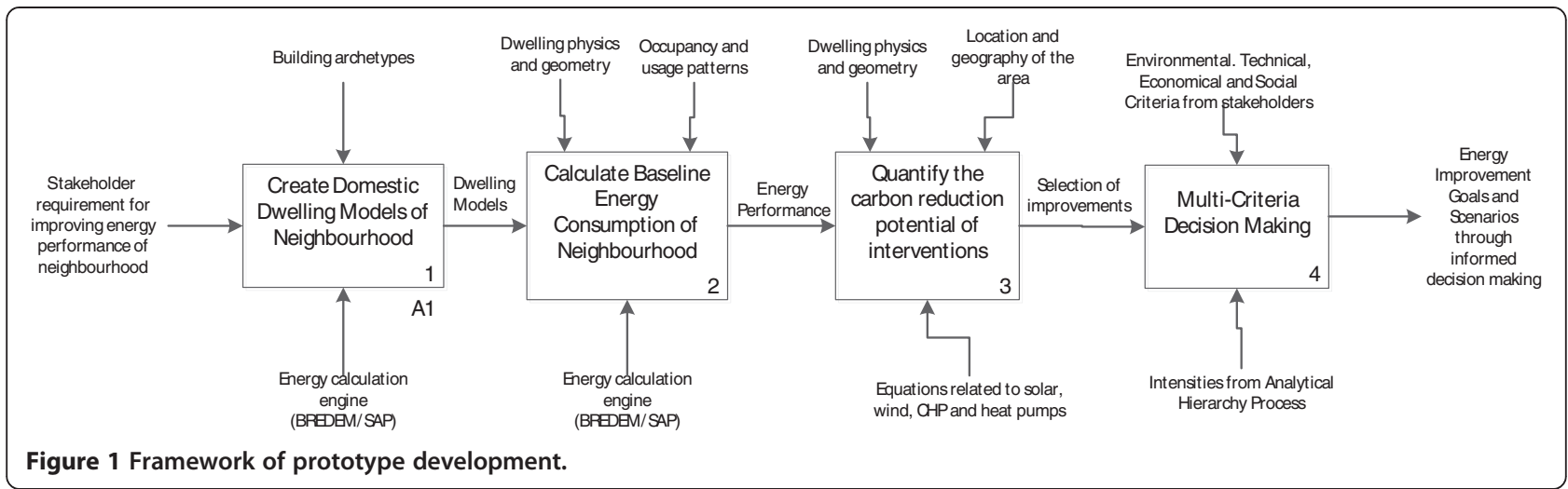

- Usage sub-model consisting of details on the type and use of heating system, heating controls and electrical appliances.

The detailed list of parameters required for the development of these models and the source where they can be obtained from is presented in Table 1.

The dwelling vector maps from Ordinance Survey are polygon features with address, area and footprint information included as attributes which builds the geometry model of dwellings (OS MasterMap Address Layer 2010; OS MasterMapTopography Layer 2010). Using the developer capabilities of ArcGIS, a user form is developed using Visual Basic for Applications (VBA) (Figure 3) which acts as an interface to include the information related to building physics and usage.

One of the significant advantages of using GIS based software is that the data entry process can be replicated for several dwellings that have similar characteristics. This is particularly useful in undertaking the energy assessment for terraced, semi-detached and detached houses built during similar time periods. The dwellings built in particular time period typically present similar physical characteristics as they were built to meet the needs of the relevant building specifications of that period.

\section{Calculate baseline energy consumption}

Once the dwelling models for a neighbourhood are developed with the attributes related to geometry, physics and usage of the dwellings stored, the next stage is to use these attributes for the calculation of baseline energy consumption. The ArcGIS developer capabilities allow for empirical equations such as those in SAP algorithms to be formulated into calculation tools that can source data from the recently stored attributes. The resultant data are values such as energy demand for space and water heating and electricity demand for lights and appliances. Based on the total energy used

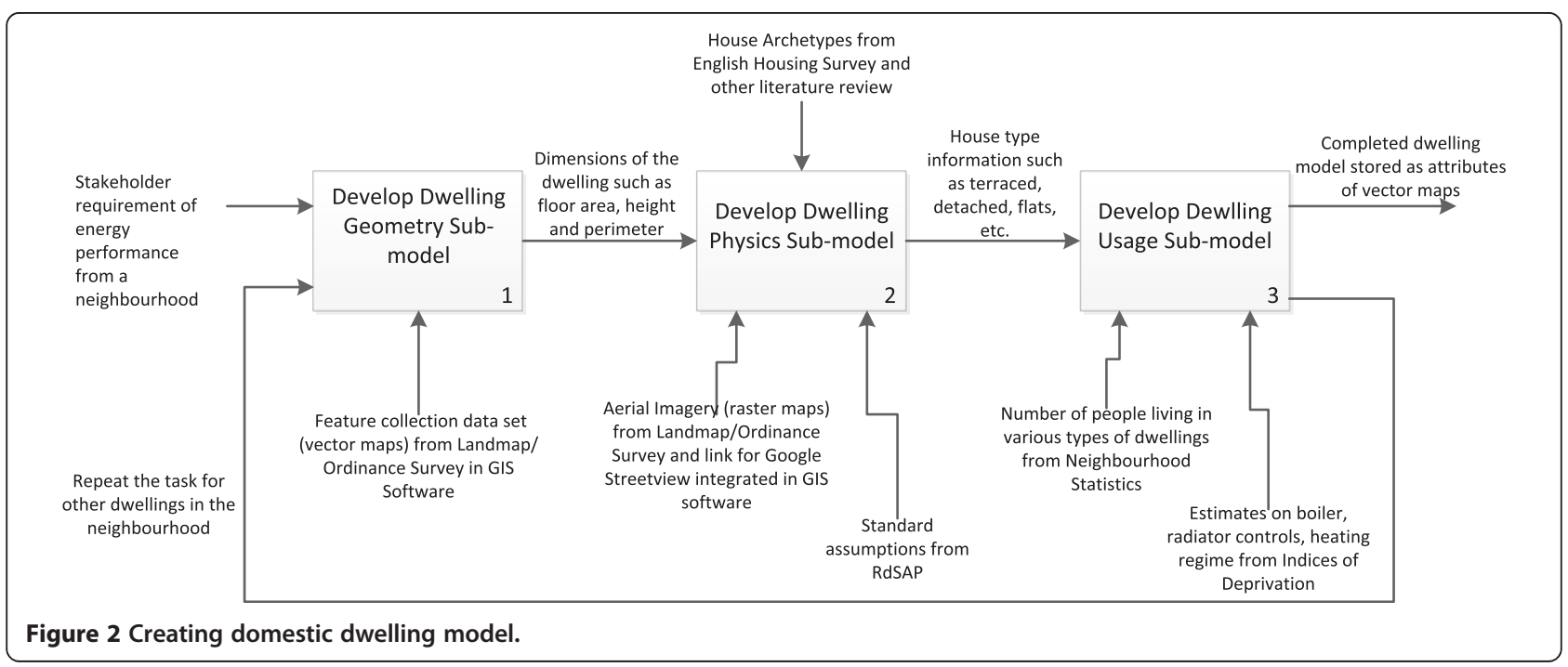


Table 1 Data and their sources for model development

\begin{tabular}{|c|c|}
\hline Information required & Data source \\
\hline \multicolumn{2}{|l|}{ Dwelling geometry sub-model } \\
\hline Number of storeys & Terrestrial imagery from Google Maps \\
\hline Floor area and perimeter & Vector map of the area from Ordinance Survey \\
\hline Height of each storey & Vector map from Landmap \\
\hline Area of the roof & Vector map of the area from Ordinance Survey \\
\hline Area of the exposed walls and windows & Vector map of the area from Ordinance Survey \\
\hline \multicolumn{2}{|l|}{ Dwelling physics sub-model } \\
\hline Degree day region & Vector map of the area from Ordinance Survey \\
\hline Height above sea level (m) & Vector map of the area from Ordinance Survey \\
\hline Mean wind speed & Data tables provided in SAP \\
\hline Level of over-shading & Raster imagery from Ordinance Survey and Google Maps \\
\hline $\begin{array}{l}\text { Dwelling detachment (mid or end terraced, semidetached, } \\
\text { detached, flat, etc.) }\end{array}$ & Vector map of the area from Ordinance Survey \\
\hline $\begin{array}{l}\text { Dwelling Age (Before 1900, 1900-1929, 1930-1949 1950-1966, } \\
\text { 1967-1975, 1976-1982, 1983-1990, 1991-1995, 1996-2002, } \\
\text { 2003-2006, } 2007 \text { - Onwards) }\end{array}$ & $\begin{array}{l}\text { Vector map of the area from Landmap, raster imagery from } \\
\text { Ordinance Survey and Google Maps }\end{array}$ \\
\hline U Value for walls and windows & Inferred from age of the building and raster imagery \\
\hline U Value for floor and roof & Inferred from age of the dwelling \\
\hline Draught proofing & Inferred from economic deprivation data from ONS \\
\hline Type of window and door frame & Terrestrial imagery from Google Maps \\
\hline Orientation of windows & Raster imagery from Ordinance Survey and Google Maps \\
\hline Number of flues, chimneys & Raster imagery from Ordinance Survey and Google Maps \\
\hline Number of fans and vents & Inferred from age of the dwelling \\
\hline Presence of mechanical ventilation & Assumed no mechanical ventilation \\
\hline Type of water heater (gas, oil or solid fuel boiler, electric immersion.) & HEED \\
\hline $\begin{array}{l}\text { If hot water tank present its volume, thickness of insulation, thermostat } \\
\text { and insulation of primary pipework }\end{array}$ & Default SAP values depending on age of the dwelling \\
\hline
\end{tabular}

and insulation of primary pipework

\section{Dwelling usage sub-model}

Heating system type e.g. open, sealed, etc. and fuel e.g. gas, oil, solid fuel, electric, etc.

Efficiency of the heating system

Type of heating controls (programmers, thermostats)

Type of cooking system (electric cooker, cooking range, etc.)

Total number of lighting outlets and proportion of low energy lights

Number of occupants

Heating periods

Demand temperatures

Level of use of hot water, lights and cooking (average, below average and above average)

and the fuel supplied for space and domestic water heating, the total amount of $\mathrm{CO}_{2}$ is computed. Based on the level of energy consumption, ArcGIS allows developing thematic maps where areas with higher energy consumption can be identified as hotspots. An example of such thematic energy consumption is presented in Figure 4.
HEED and EHCS

Inferred based on HEED and EHCS data

Inferred based on HEED and EHCS data

Inferred based on HEED and EHCS data

Inferred based on economic deprivation data from ONS, HEED and EHCS data

Census data from ONS

Inferred based on economic deprivation data from ONS

Inferred based on economic deprivation data from ONS

Inferred based on economic deprivation data from ONS
The lowest geographical level on which the data from the Office of National Statistics is aggregated is the Lower Level Super Output Area (LLSOA). LLSOAs have a minimum population of 1,000 equating to around 400 households. An energy calculation output for one such LLSOA based on the framework described is depicted in Figure 5. 


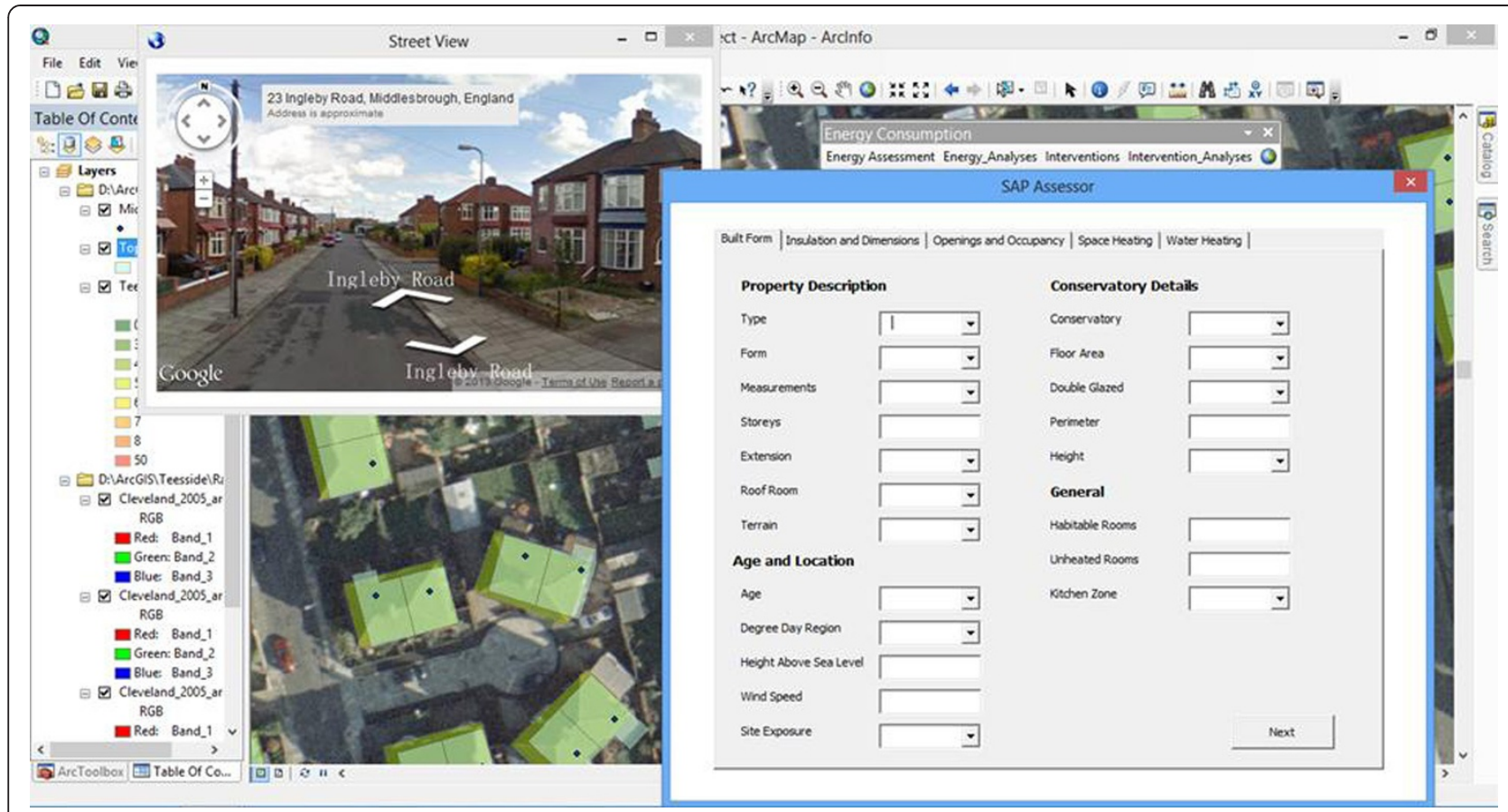

Figure 3 Userform to input data and create dwelling models.

\section{Quantify carbon reduction potential}

Subsequent to identifying the baseline energy consumption and associated $\mathrm{CO}_{2}$ levels, the next task is to identify which energy efficiency and renewable energy interventions are applicable to the area and what are their energy saving / energy generation potentials. The most common energy efficiency and renewable energy interventions within UK are floor, roof and wall insulation, solar photo voltaic and solar thermal panels, condensing combination boilers, wind turbines, micro-combined heat and power systems and air and ground source heat pumps (Boardman 2007).

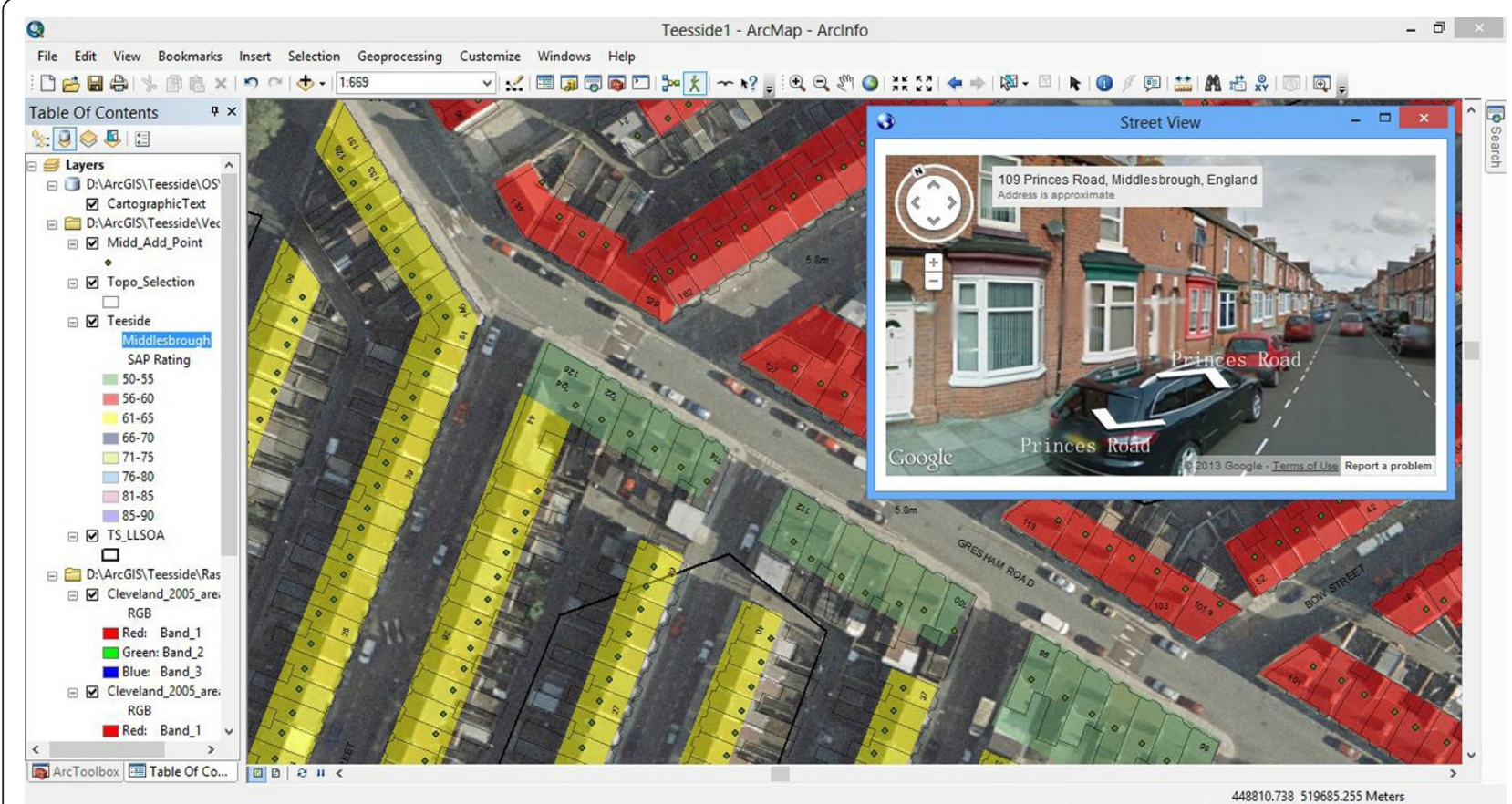

Figure 4 Thematic display of dwelling energy consumption levels. 


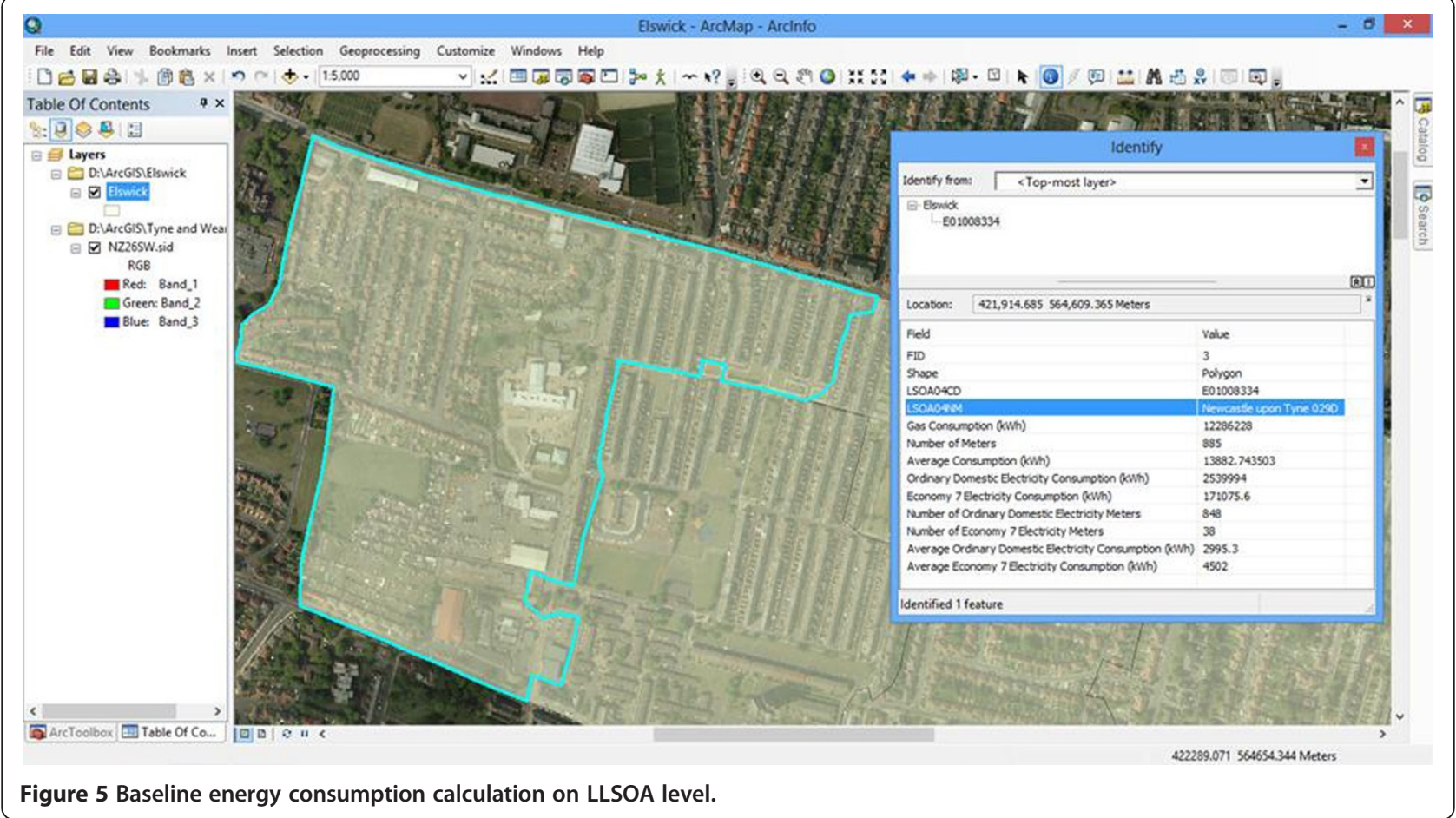

Using the UK wind speed database available from the DECC (2013) as shown in Figure 6; decisions can be made if the areas meet the space and wind speed requirements. Based on the wind speed, and the size of the wind turbine that could be installed, the wind potential of the area is identified. The dwelling models contain information on the orientation and area of roof. Using ArcGIS querying capabilities, dwellings having south facing roof are identified (Figure 7). SAP algorithms provide equations for calculation of solar potential based on roof orientation and area.

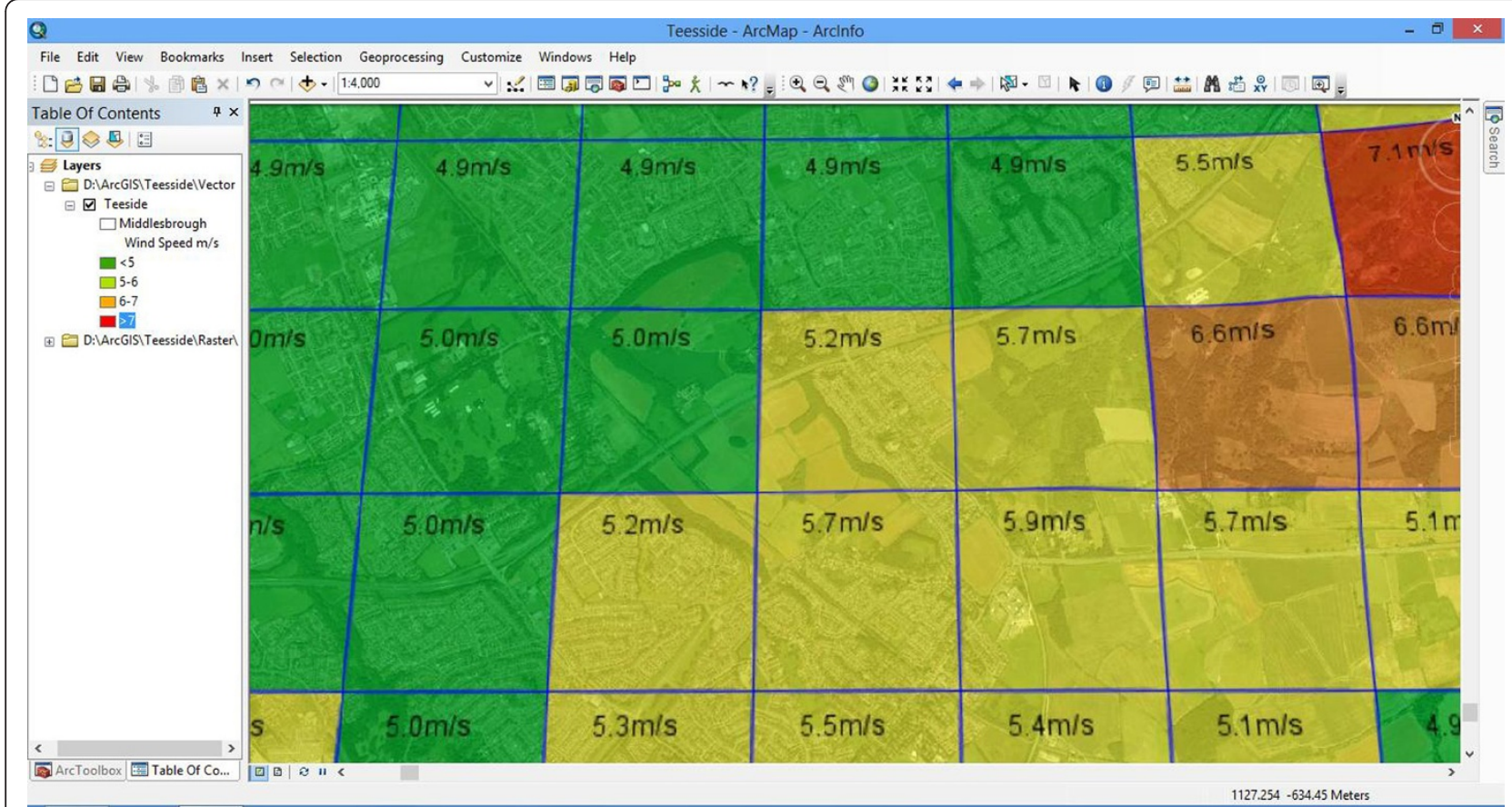

Figure 6 UK wind speed database. 


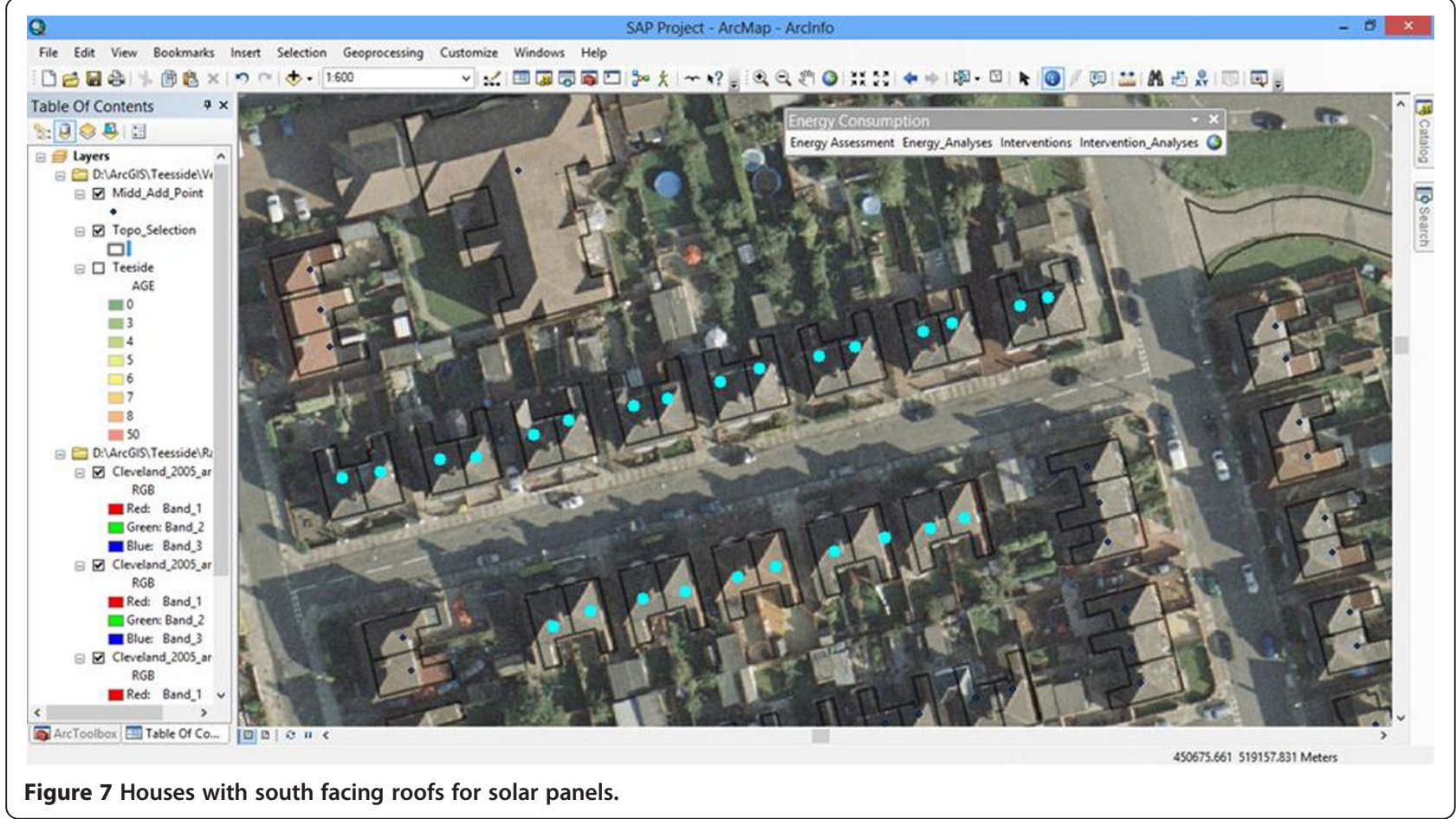

The Ordinance Survey maps along with the actual building foot-print also show the measurements of area around the property. This information is used to select dwellings having large and accessible backyards as they have a potential for installation of ground source heat pumps (Figure 8). As the heat demand of the dwellings is now known, the potential for a heat pump can be calculated using equations from SAP algorithms.

Currently equations are developed to estimate the energy savings (kWh/annum), reduction in $\mathrm{CO}_{2}(\mathrm{~kg} /$ annum) and

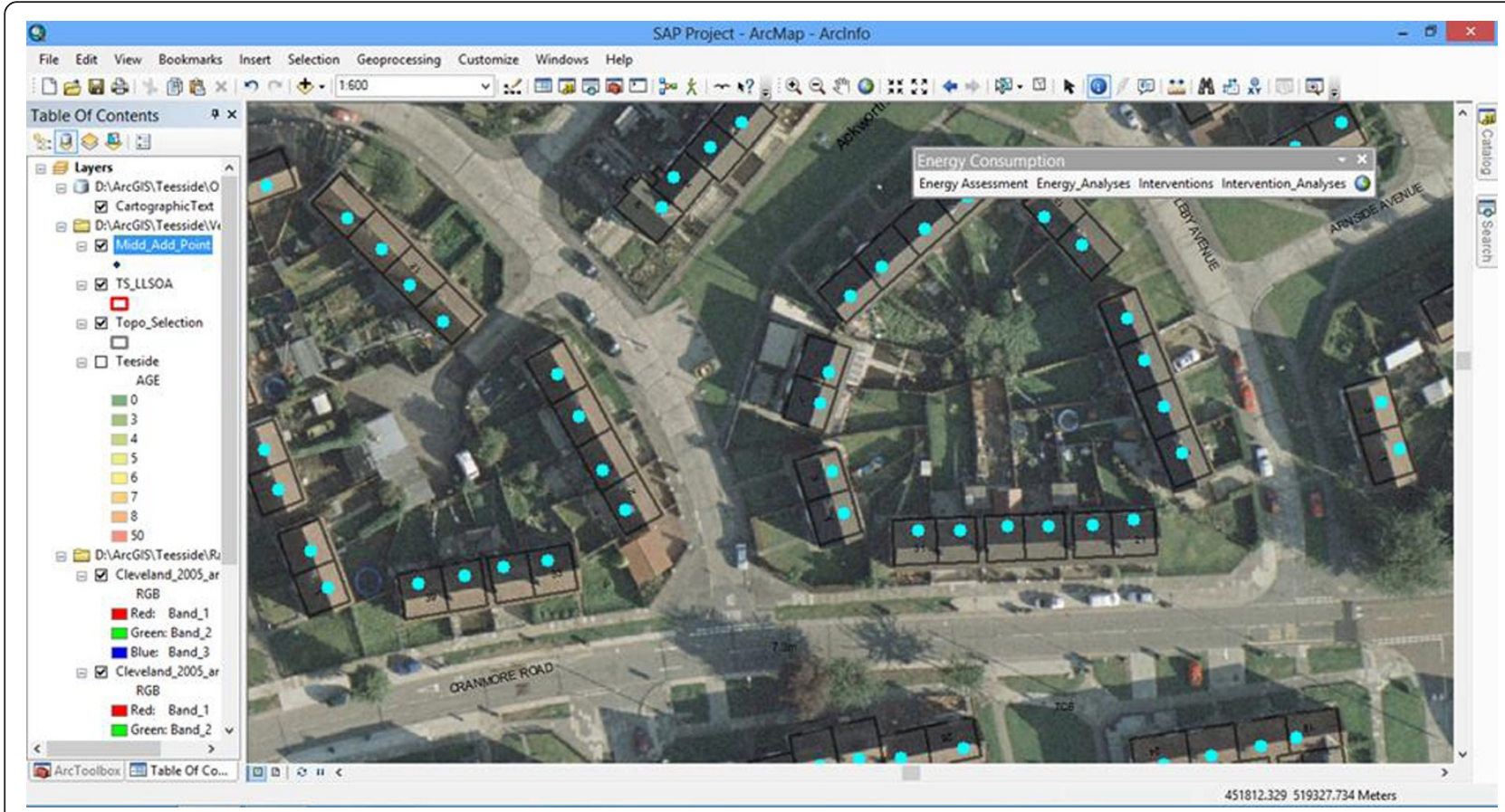

Figure 8 Dwellings with potential for heat pumps. 
savings ( $£ /$ annum) for standalone interventions. Energy savings from some interventions will be different if they were installed as combination, for e.g. an air source heat pump will provide more savings for a house without eternal wall insulation or filled cavity wall. Where the house is well insulated, the heat pumps will not require much energy to produce and hence the savings will be less and payback time will be higher. Work is currently being undertaken to address this issue.

\section{Decision support system}

Energy planning decisions are complex as several parameters are involved in the process thus necessitating a decision support system. Furthermore, as the case with most energy-related decisions, various groups of decision makers are involved. Multi-criteria decision making (MCDM) deals with making decisions in presence of multiple stakeholders' criteria and alternatives (Wang et al. 2009). MCDM can be further divided into MultiObjective Decision Making (MODM) and Multi-Attribute Decision Making (MADM). Several methods exist in each of the above categories. In MODM, the alternatives are not predetermined, but instead a set of objective functions is optimised to a set of constraints. In MADM a small number of alternatives are evaluated against a defined set of attributes. In either case, a criterion is the basis for a decision which can be measured and evaluated quantitatively or qualitatively (Pohekar and Ramachandran 2004). Analytical Hierarchy Process (AHP) is one such attributebased process developed by Saaty (1980). AHP decomposes a complex problem into a hierarchy with a goal (objective) at the top and criteria and sub-criteria at subsequent lower levels. Elements at a given hierarchy are compared in pairs to assess their relative preference with respect to each of the elements at the next higher level. A scale of 1-9 is used to assess the intensity with 1 indicating equal importance and 9 extremely high importance (Saaty, 1980). More importantly, the AHP supports tradeoffs with intangible and tangible values. As this approach is considering the social perspective along with environmental, technical and economic factors, the AHP is selected as the trade-off method of the present research.

AHP has been used for energy source assessment in various studies undertaken to select between interventions such as wind farm, solar energy, geothermal, hydroelectric, etc. based on multiple criteria (Akash et al. 1999; Gamboa and Munda 2007; Georgopoulu et al. 2003; Erol and Kilkis 2012). In this research, AHP is used to rank following alternatives:

- Annual Reduction in $\mathrm{CO}_{2}$ levels

- Initial Investment (fixed cost and grants received)

- Return on investment (annual running cost to user and savings made through feed-in-tariff)
- Social acceptability

- Ease of implementation (access to resources and timeline)

A pairwise comparison is then undertaken for the following improvement measures for each of the above criteria (second hierarchy).

- Solar photovoltaic (PV)

- Wind turbines

- Micro-combined heat and power pump ( $\mu$-CHP)

- Condensing boiler

- Air source heat pumps (ASHP) and ground source heat pumps (GSHP)

- Fabric change (roof, floor and wall insulation and double glazed windows

A user-form similar to the one presented in Figure 3 is prepared for decision support. It allows users to input intensities during pairwise comparison. The intensities assigned during pairwise comparison are converted into square matrices. The matrices are evaluated to identify the eigenvectors, which represent the weighting. The weighting for each alternative for each criterion (second hierarchy) is then multiplied by the weighting of the criteria (first hierarchy). A sum of these products across all criteria provides the final ranking of improvement measures (Saaty, 1980).

Thus, the tool enables stakeholders to assess the interventions that they are considering. So for example if a social housing provider is trying to decide if it would be more effective in terms of reducing $\mathrm{CO}_{2}$ emissions to install solar PV or ground source heat pump this tool will allow them to understand the cost and $\mathrm{CO}_{2}$ implications along with other criteria for each of these interventions. The stakeholders can then engage with appropriate building engineering companies and architects in installing these improvement measures.

\section{Results and discussion}

To validate the framework, baseline energy calculations were undertaken on a set of dwellings owned by a social housing provider in Middlesbrough, UK. The social housing providers have a regulatory requirement to maintain an energy performance certificate (EPC) for their properties. Therefore, the energy performance of the dwellings estimated by the approach of the present research can be compared with the energy performance calculated from actual survey of the property. Properties of various age and detachment were selected to ensure adequate representation of different archetypes. The results from the validation are presented in Table 2 and indicate that the estimated energy performance is within a maximum range of $\pm 8 \%$ of the actual energy performance provided by the social housing provider. The average error over the 34 
Table 2 Data and their sources for model development

\begin{tabular}{|c|c|c|c|c|c|c|c|}
\hline No. & Actual Energy $\left(\mathrm{kWh} / \mathrm{m}^{2}\right)$ & Estimated Energy $\left(\mathrm{kWh} / \mathrm{m}^{2}\right)$ & Error & No. & Actual Energy $\left(\mathrm{kWh} / \mathrm{m}^{2}\right)$ & Estimated Energy $\left(\mathrm{kWh} / \mathrm{m}^{2}\right)$ & Error \\
\hline 1 & 298.7837 & 303.00 & $1.41 \%$ & 18 & 166.1845 & 166.07 & $-0.07 \%$ \\
\hline 2 & 191.6192 & 188.00 & $-1.89 \%$ & 19 & 147.8607 & 147.35 & $-0.35 \%$ \\
\hline 3 & 187.522 & 189.00 & $0.79 \%$ & 20 & 165.0032 & 166.53 & $0.93 \%$ \\
\hline 4 & 242.8596 & 241.00 & $-0.77 \%$ & 21 & 215.8848 & 205.09 & $-5.00 \%$ \\
\hline 5 & 174.995 & 182.88 & $4.51 \%$ & 22 & 189.8272 & 196.54 & $3.54 \%$ \\
\hline 6 & 176.6468 & 177.18 & $0.30 \%$ & 23 & 285.2347 & 274.00 & $-3.94 \%$ \\
\hline 7 & 190.0774 & 194.00 & $2.06 \%$ & 24 & 162.7286 & 174.91 & $7.49 \%$ \\
\hline 8 & 163.5331 & 171.82 & $5.07 \%$ & 25 & 265.662 & 272.02 & $2.39 \%$ \\
\hline 9 & 283.2615 & 282.75 & $-0.18 \%$ & 26 & 217.2638 & 228.00 & $4.94 \%$ \\
\hline 10 & 249.1428 & 249.04 & $-0.04 \%$ & 27 & 243.0846 & 254.39 & $4.65 \%$ \\
\hline 11 & 286.2131 & 272.42 & $-4.82 \%$ & 28 & 258.9484 & 261.97 & $1.17 \%$ \\
\hline 12 & 221.8962 & 233.04 & $5.02 \%$ & 29 & 260.5743 & 261.97 & $0.54 \%$ \\
\hline 13 & 361.7491 & 359.91 & $-0.51 \%$ & 30 & 304.2866 & 313.82 & $3.13 \%$ \\
\hline 14 & 272.4004 & 278.90 & $2.39 \%$ & 31 & 212.298 & 213.46 & $0.55 \%$ \\
\hline 15 & 267.3812 & 275.58 & $3.07 \%$ & 32 & 362.5949 & 357.44 & $-1.42 \%$ \\
\hline 16 & 265.7164 & 279.75 & $5.28 \%$ & 33 & 264.5559 & 261.41 & $-1.19 \%$ \\
\hline 17 & 167.6343 & 166.07 & $-0.93 \%$ & 34 & 183.3866 & 185.82 & $1.33 \%$ \\
\hline
\end{tabular}

properties is just about $1 \%$ and the standard deviation of the error is 0.03 . The results are clearly within a close proximity of the actual energy performance and hence the approach is reliable.

Subsequent to the validation, a case study is undertaken for an LLSOA in Middlesbrough. This LLSOA consists of $756 \mathrm{dwellings}$ with a majority of terraced houses followed by a small number of semi-detached and detached houses. The annual energy consumption details for these house types estimated using the approach developed in this research is presented in Table 3. The results show an annual energy consumption of just over 16.5 GWh for the 756 dwellings in the LLSOA. This computes to an average energy consumption of $21.85 \mathrm{MWh}$ per dwelling per year within the LLSOA. The national average energy consumption estimated for domestic dwellings is $19.8 \mathrm{MWh}$ (OFGEM 2011). The estimated energy performance is approximately $10 \%$ higher than the national average. The results can however be considered consistent as most of the dwellings in this LLSOA are built prior to world war two and have low insulation standards (HEED 2012).

The prototype was further used to estimate the potential energy saving from the dwellings in the same LLSOA. The

Table 3 Energy consumption in an LLSOA

\begin{tabular}{lll}
\hline Dwelling type & Number & Energy consumption (kWh/Annum) \\
\hline Terraced & 719 & $15,948,608$ \\
Semi-detached & 23 & 357,700 \\
Detached & 14 & 265,387 \\
Total & 756 & $16,571,695$ \\
\hline
\end{tabular}

average wind speed in this area of Middlesbrough was less than the required $5 \mathrm{~m} / \mathrm{s}$ and was thus not considered suitable (DECC 2013). Since most dwellings in this area are terraced houses, space is a constraint for GSHP, hence only ASHP are considered. Table 4 shows the results from the analysis of various interventions including changes to building fabric and installation of Solar PV, $\mu$-CHP, condensing boiler and ASHP.

Fixed cost is based on the costs for individual dwellings provided by the Energy Savings Trust. Grants are typically available to energy suppliers, councils and social housing providers under the CESP and CERT that can significantly contribute towards the fixed costs and can help in bring down the costs indicated in Table 4 (DECC 2011a). Furthermore, under the UK Government's feedin-tariff, payments are made to dwellings for each $\mathrm{kWh}$ of energy generated using micro-generation technologies which includes Solar PV and $\mu$-CHP. This payment is made for 20 years from date of installation. Contribution from this feed-in-tariff has been included in the annual savings presented in Table 4. The lifetime of Solar PV is considered as 25 years and $\mu$-CHP is considered as 20 years although these technologies can last typically longer. The tariffs for ASHP were expected to be available in September 2012; however, at the time of writing this paper, the tariffs were not available and are hence not included in the annual savings. The lifetime for all technologies other than Solar PV and $\mu$-CHP is considered as 30 years.

The results indicate that for this LLSOA, fabric insulation and use of $\mu$-CHP offer the most $\mathrm{CO}_{2}$ 
Table 4 Analyses of interventions for an LLSOA in Middlesbrough

\begin{tabular}{|c|c|c|c|c|c|}
\hline Intervention & Fixed cost & Energy saved (MWh/Year) & $\mathrm{CO}_{2}$ saved (Tons/Year) & Annual savings & Lifetime savings \\
\hline Fabric Change & $£ 5,973,156$ & 9,084 & 1,795 & $£ 281,090$ & $£ 8,432,708$ \\
\hline Solar PV & $£ 4,309,200$ & 631 & 127 & $£ 217,123$ & $£ 5,428,080$ \\
\hline$\mu-\mathrm{CHP}$ & $£ 1,814,400$ & 1,311 & 678 & $£ 259,308$ & $£ 5,186,160$ \\
\hline Condensing Boiler & $£ 1,209,600$ & 585 & 115 & $£ 24,158$ & $£ 483,179$ \\
\hline ASHP (Under-floor) & $£ 6,804,000$ & 4,005 & 793 & $£ 123,984$ & $£ 3,719,520$ \\
\hline ASHP (Radiator) & $£ 4,536,000$ & $-1,037$ & -205 & $-£ 32,130$ & $-£ 963,900$ \\
\hline
\end{tabular}

reduction potential for investment made. The use of ASHP using radiators as heat emitting source currently offer no savings in energy used due to their low efficiencies. The ASHP using under-floor heating as heat emitting source appear to have good impact on $\mathrm{CO}_{2}$ reduction however is currently cost intensive. Further analyses of the results show that, just by improving the fabric of the building through insulation of solid walls and roof and installation of low emissivity double glazed windows can reduce the energy demand by 9,084 MWh or just over $41.5 \%$. Installation of condensing boilers can contribute towards reducing energy demand and installation of $\mu-\mathrm{CHP}$ and solar PV contribute towards electricity generation, thus reducing the demand from the national grid.

To test the decision making process, the information presented in Table 4 was presented to a planner representing one of the stakeholders. The planner was asked to undertake pairwise comparison for criteria and improvement measures. The intensities assigned were developed as matrices to arrive at final weighting. The prototype has interfaces to assign intensities and then visualise the final rankings.

Table 5 presents the summary of the pairwise comparison of the criteria and the alternatives weighted against each criterion. The results indicate that fabric insulation is ranked as the highest followed by $\mu-\mathrm{CHP}$, solar PV, condensing boiler and ASHP. Based on the rankings achieved, changes to the building fabric can be undertaken as a priority followed by installation of $\mu$-CHP. In this way the tool enables informed decisions to be made regarding implementation of energy policies. The choice of the energy planner is consistent with the findings in Table 4 that fabric insulation provides the largest opportunity for reducing energy demand. This scenario may however be different for another LLSOA where housing fabric may be of higher standard and other means of energy improvement have to be identified.

\section{Conclusion}

A methodology that integrates visual systems, energy related databases and multi-criteria decision analysis to enable energy assessment and evaluation of various energy efficiency and renewable energy interventions for the housing stock was presented. The methodology was prototyped in a proof-of-concept tool, validated and tested with the involvement of a local authority on a housing stock composed of 756 dwellings. The prototype made use of a GIS platform, aerial and terrestrial imagery, digital maps and information from various national statistics and databases. The validation has showed that the developed methodology and prototype provide reliable estimates of energy consumption and enables a systematic analysis of various energy efficiency and renewable energy interventions. The developed methodology and prototype fill an important gap in the literature as there are no tools that enable both the evaluation of energy consumption and the assessment of energy efficiency and renewable energy interventions. In addition, the use of the tool showed the potential of reducing energy consumption and $\mathrm{CO}_{2}$ emission while considering the intangible criteria such as social acceptance and ease of implementation associated with each improvement strategy. Therefore, the tool presents stakeholders with opportunity not only to identify the baseline energy performance of their housing stock at the neighbourhood level, but also to assess the impact of different scenarios for $\mathrm{CO}_{2}$ reduction.

The findings presented in this paper clearly illustrate that the methodology and proof-of-concept tool can be used by local authorities, town planners and social housing providers

Table 5 AHP used in decision making process

\begin{tabular}{|c|c|c|c|c|c|c|}
\hline Alternative & $\mathrm{CO}_{2}$ reduced & Initial invest. & Return on invest. & Social accept. & Ease of implemen. & $\overline{\text { Goal }}$ \\
\hline Fabric Change & 0.1403 & 0.0550 & 0.0674 & 0.0359 & 0.0219 & $32.05 \%$ \\
\hline Micro CHP & 0.1103 & 0.0801 & 0.0517 & 0.0282 & 0.0125 & $28.29 \%$ \\
\hline Solar PV & 0.0663 & 0.0582 & 0.0349 & 0.0170 & 0.0086 & $18.50 \%$ \\
\hline Boiler & 0.0359 & 0.0561 & 0.0136 & 0.0092 & 0.0048 & $11.95 \%$ \\
\hline ASHP & 0.0218 & 0.0451 & 0.0093 & 0.0056 & 0.0104 & $9.21 \%$ \\
\hline
\end{tabular}


to make informed decisions with regard to the implementation of energy policies and initiatives. Building engineering companies and architects can use the methodology and prototype to undertake dwelling specific analysis during installation of interventions. These can altogether significantly contribute to meeting $\mathrm{CO}_{2}$ emission reduction targets. Added to this it greatly reduces costs and simplifies the process by eliminating the need for drive-by surveys, saving a large amount of time and resources.

Future development of the tool will involve identification of the impact of interventions and the development of a more accurate calculation of the rate of return of investment based on inflation indices.

\section{Competing interests}

The authors declare that they have no competing interests.

\section{Authors' contribution}

AM is the main contributor to this article. The article is part of an outcome of the research undertaken by $\mathrm{AM}$ as a part of his PhD. MK was involved in compilation and proof-reading of the article. TC and ND supervised this research undertaken by AM. All authors read and approved the final manuscript.

Received: 30 January 2013 Accepted: 3 May 2013

Published: 9 July 2013

\section{References}

Akash, B. A., Mamlook, R., \& Mohsen, M. S. (1999). Multicriteria selection of electric power plants using analytical hierarchy process. Electric Power Systems Research, 52(1), 29-35.

All Party Urban Development Group. (2008). Greening UK cities' buildings. London, UK: All Party Urban Development Group.

Boardman, B. (2007). Home Truths: A low carbon strategy to reduce UK housing emissions by $80 \%$ by 2050. Oxford, UK: University of Oxford's Environmental Change Institute.

Boardman, B., Darby, S., Killip, G., Hinnels, M., Jardine, C. N., \& Palmer, J. (2005). 40\% house. Oxford, UK: University of Oxford's Environmental Change Institute.

Cheng, V., \& Steemers, K. (2011). Modelling domestic energy consumption at district scale: A tool to support national and local energy policies. Environmental Modelling \& Software, 26, 1186-1198.

Communities and Local Government. (2012). English Housing Survey 2010-11. London, UK: Department of Communities and Local Government.

DECC. (2009). Community Energy Saving Programme. Department of Environment and Climate Change Consultation.

DECC. (2011a). Evaluation synthesis of energy supplier obligation policies. London, UK: Department of Energy \& Climate Change.

DECC. (2011b). The Green Deal and Energy Company Obligation. London, UK: Department of Energy \& Climate Change.

DECC. (2013). Wind Speed Database. http://tools.decc.gov.uk/en/windspeed/ default.aspx Accessed Jan 25, 2013

DECC/BRE. (2010). The Government's Standard Assessment Procedure for Energy Rating of Dwellings. Watford: Building Research Establishment.

Environmental Systems Research Institute. (2010). A quick tour of what's new in ArcGIS 10. http://help.arcgis.com/EN/ArcGISDesktop/10.0/help/index.html\#// 00qp0000000p000000.htm. Accessed December 19, 2011.

Erol, O., \& Kilkis, B. (2012). An energy source policy assessment using analytical hierarchy process. Energy Conversion and Management, 63, 245-252.

Firth, S. K., Lomas, K. J., \& Wright, A. J. (2010). Targeting household energy-efficiency measures using sensitivity analysis. Building Research and Information, 38(1), 24-41.

Fung, A. S. (2003). Modeling of National and regional energy consumption and associated greenhouse gas emissions. PhD Thesis. Dalhousie University.

Gamboa, G., \& Munda, G. (2007). The problem of windfarm location: a social multi-criteria evaluation framework. Energy Policy, 35(3), 1564-1583.

Georgopoulu, E., Sarafidis, Y., Mirasgedis, S., Zaimi, S., \& Lalas, D. P. (2003). A multiple-criteria decision-aid approach in defining national priorities for greenhouse gases emissions reduction in the energy sector. Europen Journal of Operational Research, 146, 199-215.
Goodchild, M. F. (2009). Geographic information systems and science: Today and tomorrow (pp. 1037-1043). Xuzhou: Procedia Earth and Planetary Science.

Gupta, R. (2009). Moving towards low-carbon buildings and cities: experiences from Oxford, UK. International Journal of Low-Carbon Technologies, 4, 159-168.

H.M. Government. (2008). Climate Change Act. London: The Stationery Office Limited.

Haas, R., \& Schipper, L. (1998). Residential energy demand in OECD-countries and the role of irreversible efficiency improvements. Energy Economics, 20(4), 421-442.

HEED. (2012). Area Summary Report (Middlesbrough, Middlesbrough South and East Cleveland). Energy Savings Trust.

Hirst, E., Lin, W., \& Cope, J. (1977). A residential energy use model sensitive to demographic, economic, and technological factors. The Quarterly Review of Economics and Finance, 17(2), 7-22.

Hourcade, J. C., Jaccard, M., Bataille, C., \& Gershi, F. (2006). Hybrid modeling: new answers to old challenges. Energy Journal(Special Issue), 1-12.

House of Lords. (2008). The EU's Target for Renewable Energy: 20\% by 2020. London: The Stationery Office Limited.

Jaccard, M., Bailie, A., \& Nyboer, J. (1996). CO2 emission reduction costs in the residential sector: Behavioral parameters in a bottom-up simulation model. Energy Journal, 17(4), 107-134.

Johnston, D. (2003). A physically based energy and carbon dioxide emission model of the UK housing stock. Leeds, UK: Leeds Metropolitan University.

Jones, P., Patterson, J., \& Lannon, S. (2007). Modelling the built environment at an urban scale - energy and health impacts in relation to housing. Landscape and Urban Planning, 83, 39-49.

Kassem, M., Dawood, N., \& Mitchell, N. (2012). A decision support system for the selection of curtain wall systems at the design development stage. Construction Management and Economics, 30, 1039-1053.

Kavgic, M., Mavrogianni, A., Mumovic, D., Summerfield, A., Stevanovic, Z., \& Djurovic-Petrovic, M. (2010). A review of bottom-up building stock models for energy consumption in the residential sector. Building and Environment, 45, 1683-1697.

Larsen, B. M., \& Nesbakken, R. (2004). Household electricity end-use consumption: results from econometric and engineering models. Energy Economics, 26(2), 179-200.

Natarajan, S., \& Levermore, G. J. (2007). Domestic futures-Which way to a lowcarbon housing stock? Energy Policy, 35(11), 5728-5736.

Office of the Deputy Prime Minister. (2010). Planning Policy Statement 12: Local Development Frameworks. London: Stationary Office.

OFGEM. (2011). Typical domestic energy consumption figures. London, UK: OFGEM

OS MasterMap Address Layer. (2010). Ordinance Survey, GB. Middlesbrough: Coverage.

OS MasterMapTopography Layer. (2010). Ordinance Survey, GB. Middlesbrough: Coverage.

Palmer, J., \& Cooper, I. (2011). Great Britain's housing energy fact file. London, UK: Department of Energy and Climate Change.

Pohekar, S. D., \& Ramachandran, M. (2004). Application of multi-criteria decision making to sustainable energy planning - A review. Renewable and Sustainable Energy Reviews, 8, 365-381.

Rylatt, R. M., Gadsden, S. J., \& Lomas, K. J. (2003). Methods of predicting urban domestic energy demand with reduced datasets : a review and a new GIS based approach. Building Senvices Engineering Research and Technology, 24(2), 93-102.

Saaty, T. L. (1980). The analytic hierarchy process. New York: Macgraw-Hill.

Shorrock, L. D., \& Dunster, J. E. (1997). The physically-based model BREHOMES and its use in deriving scenarios for the energy use and carbon dioxide emissions of the UK housing stock. Energy Policy, 25(12), 1027-1037.

Swan, L. G., \& Ugursal, V. I. (2009). Modeling of end-use energy consumption in the residential sector: A review of modeling techniques. Renewable and Sustainable Energy Reviews, 13, 1819-1835.

Tuladhar, S. D., Yuan, M., Bernstein, P., Montgomery, W. D., \& Smith, A. (2009). A top-down bottom up modelling approach to climate change policy analysis. Energy Economics, 31(Supp. 2), S223-S234.

Wang, J. J., Jing, Y. Y., Zhang, C. F., \& Zhao, J. H. (2009). Review on multi-criteria decision analysis aid in sustainable energy decision-making. Renewable and Sustainable Energy Reviews, 13, 2263-2278.

Wilson, D., \& Swisher, J. (1993). Exploring the gap. Top-down versus bottom-up analyses of the cost of mitigating global warming. Energy Policy, 21(3), 249-263.

Wright, A. (2008). What is the relationship between built form and energy use in dwellings? Energy Policy, 36, 4544-4547.

doi:10.1186/2213-7459-1-7

Cite this article as: Mhalas et al:: A visual energy performance assessment and decision support tool for dwellings. Visualization in Engineering 2013 1:7 